\title{
AS CONTRIBUIÇÕES DE ROBERT BOYLE À QUÍMICA FACE A UMA VISÃO INTERDISCIPLINAR COM A GEOGRAFIA
}

\author{
L. I. Medeiros \\ Aluna da curso de Licenciatura Plena em Geografia do Centro Federal de Educação \\ Tecnológica do Rio Grande do Norte; leticiageog@yahoo.com.br
}

Recebido em outubro de 2004 e Aceito em abril de 2005

\section{RESUMO}

No século XVII, o físico e químico irlandês, Robert Boyle, merece um papel de destaque na química pois ele auxiliou no desenvolvimento teórico desta ciência. Em 1660, ao publicar sua primeira obra científica não-aristotélica sobre a pressão atmosférica e o vácuo, baseado nos trabalhos de Galileu, Pascal e Torricelli, Boyle travou um conflito de idéias com o aristotélico Thomas Hobbes. Em 1662, em resposta aos ataques de Hobbes, Boyle publica um livro onde consta a lei da relação entre a pressão e o volume dos gases. Em 1670, através de uma experiência feita com um tubo de vidro em forma de J, ele concluiu a lei dos gases, cuja declara que em uma temperatura constante, o volume e a pressão de um gás são inversamente proporcionais. Objetiva-se com esta pesquisa promover a interdisciplinaridade entre as disciplinas da química e da ciência geográfica, através de um resgate histórico sobre a lei dos gases, gerando uma discussão acerca da aplicabilidade, exploração, perfuração, processamento e produção do gás na atualidade. O trabalho foi desenvolvido a partir de uma pesquisa bibliográfica e na internet acerca do tema. Tomando por base os estudos de Robert Boyle, pode-se promover uma interdisciplinaridade entre as disciplinas da química e da geografia, analisando quimicamente a lei dos gases e promovendo uma discussão geográfica acerca da exploração, perfuração de poços, o processamento do gás, aplicabilidade do gás na indústria, em veículos, domicílios e como uma das principais fontes alternativas da atualidade para a ampliação da matriz energética brasileira.

Palavras-chave: lei dos gases; energia alternativa e interdisciplinaridade. 


\section{AS CONTRIBUIÇÕES DE ROBERT BOYLE À QUÍMICA FACE A UMA VISÃO INTERDISCIPLINAR COM A GEOGRAFIA}

\section{ROBERT BOYLE (1627-1691)}

O surgimento da Química - como uma coleção de informações - deu-se na Alexandria, grande centro comercial do Egito. Quando os árabes invadiram a região, absorveram esse conhecimento (que os habitantes da cidade denominavam chemia) e o desenvolveram, descobrindo e investigando inúmeras substâncias. Assim nasceu a Alquimia, a precursora da Química.

O homem na Idade Média tinha sua atenção fixada em Deus e no Céu. Com o Renascimento, no século XVI, isso mudou pouco a pouco. O investigador no preparo de medicamentos, sobo estímulo de Phillipus Aureolus Paracelsus (1493-1541), dirige os seus esforços para uma química a serviço do ser humano.

Apenas no século XVII é que a Química se transformará em um campo de estudo com objetivos e métodos perfeitamente delimitados. Nesta evolução coube um papel de destaque ao físico e químico irlandês, Robert Boyle. Desde sua adolescência, Boyle compreendera a relevância fundamental dos experimentos e a visão mecanicista proposta por Descartes. Boyle escreveu um importante livro, The Sceptical Chemist ${ }^{1}$ o químico inquisidor (scheptical é uma palavra inglesa empregada em filosofia), no qual censura qualquer tipo de mistificação, apontada como obstáculo para o conhecimento científico, bem como as concepções errôneas sobre elemento químico. Neste livro, ele demoliu todas as concepções alquímicas aristotelianas, tendo, por isso mesmo, abandonado o prefixo "al" da Química. Ele concluiu que os quatro elementos aristotelianos e os "princípios" comumentemente aceitos na época não poderiam ser elementos químicos reais, desde que eles não podiam ser extraídos das substâncias, nem serem utilizados para as compor.

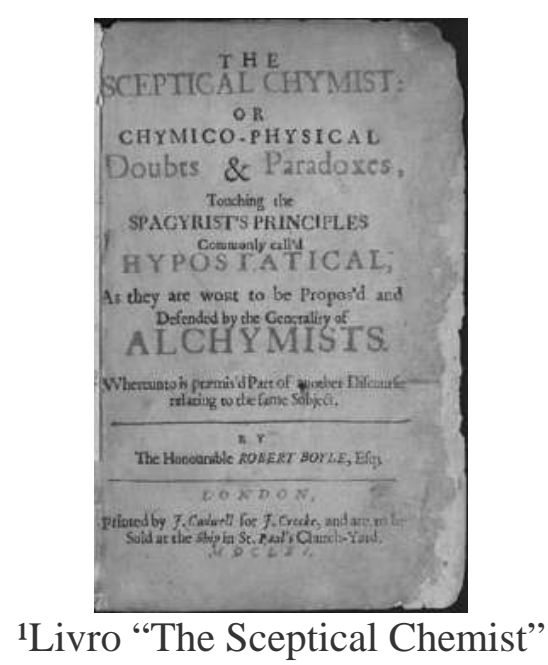

Seguindo o exemplo das obras de seu mestre Galileu, Boyle redigiu seu livro em forma de um diálogo entre três personagens - um aristotélico, um defensor das teorias da Química Médica de Paracelso e um químico cético -, tomando a posição deste último, que antevia novos horizontes para a Química. A obra conclui com a defesa da teoria atomista de Pierre 
Gassendi e do emprego de um método de raciocínio científico como o propagado por Descartes, baseado em idéias "claras e distintas". Com essas teses, Boyle salientava, de forma definitiva, como e por que a observação de substâncias individuais e suas transformações deveria constituir um tema especial de estudo. Assim, como representante de um grupo típico de cientistas ingleses dos séculos XVI e XVII - cientistas amadores, em muitos casos ocupando alta posição social, Boyle destacou-se principalmente por sua ajuda ao desenvolvimento teórico da química.

Robert Boyle nasceu na Irlanda, em 1627. Sua educação foi primorosa. Ainda criança aprendeu o latim e o francês. Em 1638, saiu da escola tradicional Eton e, em companhia de um tutor francês, partiu em viagem pela Europa. O roteiro incluía uma estada em Florença (de 1641 a 1642), onde o jovem inglês presenciou os últimos anos da vida de Galileu Galilei. Pôde, desta forma, adquirir com ele a certeza de que a experiência é a fonte dos conhecimentos científicos.

Indo para a França, entrou em contato com a obra de Pierre Gassendi, cientista e professor de Matemática no Collège de France, defensor da teoria atômica da matéria. Boyle conheceu e deu extrema atenção ao método cartesiano de raciocínio e sempre buscou, como o filósofo francês, expressar suas idéias de maneira clara e precisa. De volta à Inglaterra, começou a aplicar os conhecimentos recém-adquiridos.

Em 1644, Boyle mudou-se para Oxford, onde passou a freqüentar reuniões de um grupo de jovens interessados em desenvolver a chamada Filosofia Experimental (ciências físicas e químicas). Para defender seus propósitos, o grupo fundou inicialmente a Sociedade Real de Londres, para o desenvolvimento das ciências naturais e depois, a Royal Society, que defenderia sua fé na abordagem científica, tendo o experimentalismo como palavra de ordem.

Robert Boyle morreu em Londres, em 1691, reverenciado porcientistas da Europa e principalmente pela Royal Society.

\section{LEI DOS GASES E OUTRAS CONTRIBUIÇÕES À QUÍMICA}

Durante sua permanência em Oxford, Robert Boyle foi imensamente fecundo. Em 1660 publicou sua primeira obra científica Novas Experiências Físico-Mecânicas, Concernentes à Elasticidade do Ar e Seus Efeitos -, onde relata uma série de estudos e observações a partir dos trabalhos de Galileu, Pascal e Torricelli sobre o peso do ar (pressão atmosférica) e o vácuo.

Tratando-se de uma obra essencialmente não aristotélica, levantou grande celeuma na época: logo em seguida foram publicados dois livros com violentos ataques tanto às experiências como às interpretações de Boyle. Um desses trabalhos era de autoria de Thomas Hobbes, ardente defensor da não-existência do vácuo e da teoria do "éter" que preencheria todo o Universo.

Em 1662, Boyle publicou sua resposta aos ataques, num livro rebatendo tanto Hobbes como Linus. Na segunda metade do Apêndice - intitulado Onde Se Examina a Hipótese Funicular dos Adversários - ele incluiu sua famosa lei da relação entre a pressão e o volume dos gases. 
Em seus trabalhos sobre as relações entre pressão e volume dos gases, Boyle não faz qualquer alusão explícita à influência da temperatura nos resultados obtidos. Hoje em dia, sabe-se que a pressão de um dado volume de gás, à temperatura ambiente, aumenta em 1/273 do seu valor, para uma elevação de temperatura de 1 grau Celsius.

Em 1670, Boyle utilizou-se de um tubo de vidro² em forma de $\mathrm{J}$ com 5,18cm e vedou sua extremidade inferior. Usando mercúrio, ele aprisionou uma determinada quantidade de ar na parte vedada. Então, ele descobriu que se dobrasse o peso do mercúrio contido no tubo, o volume de ar se reduziria à metade. No entanto, caso ele reduzisse a pressão pela metade, tirando metade do mercúrio, o volume do ar dobraria. Sua conclusão está incluída na lei de Boyle, cuja declara que em uma temperatura constante, o volume e a pressão de um gás são inversamente proporcionais. Assim, o volume de um gás, por exemplo, varia na proporção inversa de sua pressão.

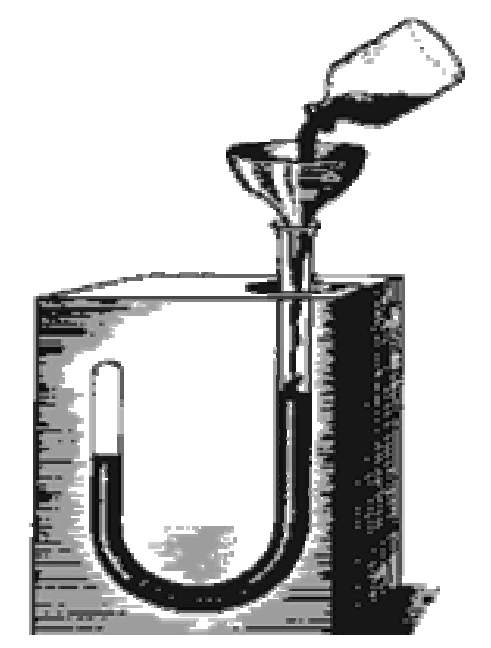

2 Tubo em “J” usado por Boyle

Atualmente, quando se pretende uma medida rigorosamente correta da relação entre pressão e volume de um gás, é indispensável que se fixe antes a temperatura empregada. Podemos enunciar a lei de Boyle $\left(\mathrm{P}_{1} \mathrm{~V}_{1}=\mathrm{P}_{2} \mathrm{~V}_{2}\right.$, $)$ da seguinte maneira: para gases ideais, a uma temperatura fixa, a pressão é inversamente proporcional ao volume.

A partir desta lei, o papel da experimentação ganhou importância. Os pesquisadores tornaram-se conscientes da possibilidade de encarar a natureza sem mistérios ou mistificações. Ficou claro que era possível obter respostas às questões propostas pela química através de experimentos bem planejados.

É no campo da química teórica que se situam as maiores contribuições do cientista inglês. Um de seus grandes méritos foi o de trazer para esta ciência a visão mecânica da natureza, que então triunfava na Física, sob a influência de Galileu. Como ele próprio dizia: "Até hoje os químicos sempre pensaram que seu trabalho fosse limitado à preparação de beberagens ou à transmutação dos metais. Em vez disso, eu procuro considerar a Química de modo diferente, não como poderia fazer um médico ou um alquimista, mas como um filósofo. 
Boyle construiu sua própria visão do universo mecânico, no qual as qualidades fundamentais eram a matéria e o movimento. Essas idéias ele as expôs no livro A Origem das Formas e Qualidades, publicado em 1666. Nele, o cientista faz a defesa da teoria atômica, afirmando que qualquer combinação química é o resultado de uma reação entre partículas elementares. Portanto, sua concepção do Universo baseava-se na existência inicial de partículas sólidas, fisicamente indivisíveis. Estas associavam-se em grupos maiores que, por sua vez, agiam como unidades nas reações químicas (é o que se conhece atualmente pelo nome de moléculas). Para ele, o tamanho e a forma dessas unidades é que dariam as propriedades físicas das substâncias.

Apesar de se destacar como teórico, Boyle era um hábil experimentador, tendo realizado várias descobertas importantes nesse campo. Desenvolveu, entre outros, o método para o isolamento do fósforo e investigou os ácidos e os álcalis e descreveu vários testes úteis para análise química qualitativa.

\section{O GÁS NUMA VISÃO INTERDISCIPLINAR}

Tomando por base os estudos do gás feito por Robert Boyle, podemos promover uma interdisciplinaridade entre as disciplinas da química e da geografia, analisando a lei de Boyle e a aplicabilidade do gás como fonte alternativa de energia, promovendo uma discussão acerca da exploração, perfuração de poços, o processamento do gás, as produções nordestina e norte-rio-grandense, além do GASBOL, o Gasoduto Bolívia Brasil. Além disso, a ciência geográfica tem interesse especial pelo estudo do gás, pois este, segundo a PETROBRAS (1997), é uma das principais fontes alternativas para a ampliação da matriz energética brasileira.

Quanto à sua aplicabilidade, o gás pode ser empregado na indústria, em veículos, em domicílios e como fonte de energia.

$\mathrm{Na}$ indústria, ele pode ser utilizado como combustível, proporcionando uma combustão limpa, isenta de agentes poluidores, ideal para processos que exigem a queima em contato direto com o produto final, como, por exemplo, a indústria ceramista e a fabricação de cimento e vidro. O gás natural pode ser utilizado como redutor siderúrgico na fabricação do aço e, de formas variadas, com matéria-prima: na indústria petroquímica, principalmente para a produção de metanol, e na indústria de fertilizantes, para a produção de amônia e uréia.

Serve também como combustível para automóveis, ônibus e caminhões, sendo denominado "gás veicular", oferecendo diversas vantagens como o baixo custo em relação a outros combustíveis, a não-eliminação de carbono nas partes internas do motor, reduzindo os custos com manutenção do carro.

O "gás domiciliar” é outro uso feito do gás. Este é um setor em constante crescimento nas cidades, demandando investimentos expressivos em conversões, em recebimento e adaptações nas residências.

Além disso, tendo em vista que a capacidade de geração das hidrelétricas brasileiras está a ponto do seu limite (basta verificarmos as medidas tomadas pelo Governo, como o horário 
de verão, visando a diminuição no consumo nas regiões Sul e Sudeste do país, além de medidas mais drásticas, como o "apagão”, que ocorreu em 2001, deixando milhares de brasileiros, literalmente, “às escuras”), o gás pode auxiliar nas indústrias termoelétricas, a partir da sua queima.

Dentre as vantagens da instalação de termoelétricas, destacam-se a geração não só de energia como também de calor e de refrigeração. O investimento nesse tipo de geração de energia é inferior ao da construção de uma hidrelétrica, além de ser menos prejudicial ao meio ambiente.

\section{EXPLORAÇÃO, PERFURAÇÃO E PROCESSAMENTO DO GÁS}

Quanto à exploração do gás natural, o papel do geólogo é o de saber aproximadamente como se formam os reservatórios e onde eles serão possivelmente encontrados, por meio da sismologia, que lhe oferece uma segura consideração sobre o tipo de rocha onde está presente o gás, e a que profundidade da crosta ele pode ser encontrado.

Quanto à perfuração de poços, uma vez determinado o local e o tamanho do reservatório (raso ou profundo), será determinado o equipamento a ser usado na superfície para perfurar o poço. Atualmente, cerca de $85 \%$ dos poços perfurados usam equipamentos de perfuração rotativos convencionais. Uma das novas tecnologias nesta área é a perfuração horizontal que é também a mais produtiva. O Brasil é o pioneiro na tecnologia de perfuração em águas profundas. As plataformas permanentes são colocadas em áreas onde serão perfurados poços múltiplos e de alta produção.

Em relação ao processamento do gás, existem dois tipos: um para o gás associado e outro para o gás não-associado. Para o gás associado, que é encontrado em reservatórios de óleo cru, dissolvido no óleo, o óleo é separado na cabeça de poço. Já o processamento do gás não-associado, ocorre separadamente do óleo. É chamado comumente de "poço-de-gás". No Nordeste, $50 \%$ das reservas correspondem a gás associado e $50 \%$ ao não-associado, conferindo maior flexibilidade à produção.

\section{GÁS NO NORDESTE E NO RIO GRANDE DO NORTE}

Estima-se que a região Nordeste apresenta um potencial de produção de gás de 18 milhões de $\mathrm{m}^{3} /$ dia. O fato das reservas nordestinas serem compostas por $50 \%$ de gás associado e $50 \%$ de não-associado, proporciona maior flexibilidade à produção. Segundo a PETROBRAS (1997), dos nove estados da região, apenas cinco produzem gás natural, sendo a Bahia o maior produtor (4,8 milhões de $\mathrm{m}^{3} / \mathrm{dia}$ ). Em segundo lugar, está o Rio Grande do Norte, com um volume diário de 2,6 milhões de $\mathrm{m}^{3}$. Os campos em terra são responsáveis por 62,8\% da produção. O Nordeste abriga 99 campos de gás, sendo 31 no Rio Grande do Norte.

Em novembro de 2002, foi inaugurado o gasoduto Pilar-Cabo, que liga os estados de Alagoas e Pernambuco, garantindo um grande impulso ao abastecimento de gás no Nordeste, permitindo o envio do gás para o Cabo de Santo Agostinho, em Pernambuco. Com isso, o sistema de distribuição de gás do Nordeste será interligado e vai ganhar um reforço de 1,2 milhão de metros cúbicos (m3) de gás por dia. 
No Rio Grande do Norte, o pólo Gás-Sal é um grande projeto de criação de novas indústrias no RN, tem como base o aproveitamento do sal, gás natural, petróleo e calcário produtos que existem com certa abundância no estado. Este funcionará na cidade de Macau. O projeto prevê a utilização do gás natural extraído pela Petrobras, para, através de usinas termoelétricas, gerar energia para a fábrica de barrilha e o petróleo como matéria prima. O projeto envolve o Governo do Estado, a FIERN, a Petrobrás, o BNB, BNDES, em parceria com capital privado. Além disso, o Rio Grande do Norte abastece o estado do Ceará através do gasoduto Guamaré-Pecém. E fornece também para os estados da Paraíba e Pernambuco, através do gasoduto Nordestão.

Uma localidade que se destaca na área de produção de gás natural no RN é o Pólo Industrial de Guamaré, que atende a 100\% do mercado de gás de cozinha do Rio Grande do Norte, segundo a PETROBRAS (1997). De acordo com esta, a elevação gradativa da produção do campo de Pescada, pela entrada em operação de novas plataformas, direcionará os excedentes de Gás de cozinha da unidade de Guamaré para o mercado consumidor do Ceará e da Paraíba.

\section{O GASODUTO BOLÍVIA - BRASIL}

O GASBOL é o gasoduto que traz o gás natural boliviano para o Brasil. A obra, iniciada em agosto de 1997 e iniciou a sua operação comercial em 1999. Esta importante obra visa o fornecimento de gás natural boliviano pelo prazo de 20 anos.

Atualmente, fornece cerca de oito milhões de m3/dia de gás natural. A estimativa para 2010, com a plena operação do GASBOL e de outras obras de porte, é que a participação do gás natural na matriz energética brasileira ultrapasse $12 \%$. Um grande salto em comparação com a participação atual de 3\%, beneficiando mais de 130 municípios de sete estados brasileiros: Mato Grosso do Sul, Rio de Janeiro, Minas Gerais, Paraná, Santa Catarina e Rio Grande do Sul.

Algumas usinas brasileiras já funcionam a partir do abastecimento de gás pelo GASBOL. Uma delas é a Trata-se da usina William Arjona, localizada em Campo Grande (MS), que está produzindo $80 \mathrm{MW}$ e consumindo $540 \mathrm{mil} \mathrm{m3/dia} \mathrm{de} \mathrm{gás} \mathrm{natural.} \mathrm{Esta} \mathrm{produção} \mathrm{no}$ MS atende a $20 \%$ do consumo de energia desse estado.

Atualmente, o produto responde por 2,4\% do consumo primário de energia.

\section{REFERÊNCIAS:}

A Alquimia e a Química. Disponível em http://www.eca.usp.br/nucleos/njr/ voxscientiae/reportagemafonso3.html Acesso em 13/10/2004.

PETROBRAS. Gás natural - Informações técnicas. Rio de Janeiro, junho/1997.

Robert Boyle. Disponível em http://www.quimica.net/emiliano/quimica_geral/ personalidades/ boyle.htm Acesso em 13/10/2004. 
SENAI. Curso básico em tecnologias do gás. Natal, 1997.

STRATHERN, P. O sonho de Mendeleiev: a verdadeira história da química. Trad. Maria Luiza X. de A. Borges. Rio de Janeiro: Jorge Zahar ed., 2002. (pp. 148-158) 